LITERATURA 



\section{PATRIA Y SEXO DE LUIS ANTONIO DE VILLENA: CONSTRUCCIÓN DE LA MEMORIA, DEL DESEO Y DE LA NACIÓN}

Sergio Coto-Rivel

\section{(c) $(7)(9)$}

Esta obra está bajo una licencia Creative Commons 



\title{
PATRIA Y SEXO DE LUIS ANTONIO DE VILLENA: CONSTRUCCIÓN DE LA MEMORIA, DEL DESEO Y DE LA NACIÓN
}

\author{
NATION AND SEX, BY LUIS ANTONO DE VILLENA: THE \\ CONSTRUCTION OF MEMORY, DESIRE AND NATION
}

Sergio Coto-Rivel

\begin{abstract}
RESUMEN
En el presente artículo nos interesamos de manera particular por la construcción narrativa del género de memorias en el texto Patria y sexo del autor español Luis Antonio de Villena. La escritura del yo en el caso de Villena realiza un importante contraste discursivo entre dos elementos opuestos y al mismo tiempo complementarios: el surgimiento del deseo sexual y el aprendizaje patriótico durante la dictadura franquista. Así entonces analizamos en primer lugar los elementos del pacto autobiográfico presentes en la narración y en segundo lugar la manera en la que el narrador construye su identidad sexual a partir de los recuerdos que evocan su juventud y el aprendizaje del patriotismo. En Patria y sexo vemos un testimonio de la construcción de la masculinidad a partir de la norma patriarcal expresada en las expectativas que el estado tiene sobre sus ciudadanos.
\end{abstract}

Palabras clave: literatura española, memorias, sexualidad, identidad nacional, siglo XX.

\begin{abstract}
In this article we are particularly interested by the narrative construction of the memoir genre in the text Patria y sexo from Spanish author Luis Antonio de Villena. The self-writing, in the case of Villena, performs an important discursive contrast between two opposite and at the same time complementary elements: the arising of the sexual desire and the patriotic learning during the Franco dictatorship. We then analyze first the elements of the autobiographical pact present on the narrative, and second, the way the narrator builds his sexual identity from memories which evoke his youth and the learning of patriotism. In Patria y sexo we see a testimony of the construction of masculinity from the patriarchal norm expressed on the expectations which the state has of its citizens.
\end{abstract}

Key words: Spanish literature, memories, sexuality, national identity, $20^{\text {th }}$ Century.

Dr. Sergio Coto-Rivel. Universidad de Nantes. Profesor investigador (Maître de conférences) en literatura y civilización latinoamericanas, laboratorio CRINI. Francia.

Correo electrónico: s.coto-rivel@hotmail.fr

Recepción: 19- 01- 2015

Aceptación: 08- 02- 2015 


\section{Introducción}

Siempre me he sentido naturalmente español [...] pero como mucha gente universitaria de mi generación, anhelosa de abrir mundos, nunca he sido nada patriota (De Villena, 2004, p. 222)

Patria y sexo (2004), texto de memorias del escritor español Luis Antonio de Villena se presenta al lector como una suerte de ejercicio parcial del recuerdo, el cual pretende aliar elementos de la vida militar en la formación de todo joven español durante el franquismo al descubrimiento del sexo y del deseo. El relato de Villena pone directamente en relación estos dos elementos a través dos momentos esenciales de la vida de un joven de su generación. Por un lado el campamento falangista de la infancia y por otro el servicio militar. Es así como los primeros momentos en los que se despierta el deseo se ven asociados a un aprendizaje del patriotismo de la época y de la formación de los ciudadanos. Por medio de una forma de la escritura del yo, Patria y sexo desarrolla las contradicciones a las que se enfrenta el autor-protagonista para conciliar el sentido estricto del sistema militar con el despertar de una sexualidad fuera de la norma. A continuación analizaremos las diferentes estrategias narrativas puestas en práctica en el texto de Villena para construir este principio de contradicción.

\subsection{Organización narrativa}

El relato está estructuralmente dividido en dos partes claramente diferenciadas que conforman narraciones independientes, ambas se encuentran íntimamente relacionadas a partir de los ejes temáticos que las estructuran, como son el descubrimiento de sí mismo en la sexualidad y las implicaciones del sujeto que se forma en un contexto cívico para servir a la patria, ambas ya expresadas desde el título de la obra. La primera parte se titula "Filos del alba (Memorias de un niño en el verano falangista)", la cual se dedica a un acontecimiento específico durante la infancia; mientras la segunda parte, "Ternura y sables (Recuerdos íntimos del servicio militar)", está centrada en un momento posterior cuando el protagonista debe cumplir con el servicio militar obligatorio.

Los acontecimientos narrados en "Filos del alba" desarrollan ampliamente elementos descritos de forma mucho más superficial, en Ante el espejo ${ }^{1}$ - veintidós años antes - como lo es la participación del narrador en un campamento de la OJE (Organización Juvenil Española), una rama constituida para adolescentes de la Falange Española y de las JONS. ${ }^{2}$ El texto consta de un capítulo único narrado en primera persona y de forma cronológica, a excepción de algunas digresiones introducidas por el narrador en las que comenta brevemente los acontecimientos que rememora. La historia comienza en el verano de 1961, cuando el protagonista es llevado por su madre a la estación de trenes de Príncipe Pío para encontrarse con sus primos (Mario y Tito), quienes tienen el encargo de cuidar al protagonista durante la duración del campamento, ya que es quien tiene menor edad de los tres: diez años. La narración se va centrando en distintos acontecimientos que marcan el desarrollo del campamento, la organización interna, la división de los asistentes en escuadras, las actividades diarias, etc.; al mismo tiempo que el narrador hace reflexiones desde dos posiciones esencialmente: en un primer caso la del hombre adulto que coincide con el presente del escritor y en un segundo caso la de las consideraciones del niño que empieza a vivir una nueva etapa de su vida.

Dos ejes se desarrollan de manera constante a través de la diégesis, los cuales se relacionan por un lado con el descubrimiento de la sexualidad y del juego erótico iniciático entre 
los adolescentes del campamento. Y por otro lado con la introducción de los niños y adolescentes en un ambiente de formación cívica que responde a la ideología de la OJE (organismo de base fascista impulsado por el franquismo). La narración concluye cuando el protagonista puede salir del campamento debido a una enfermedad dos días antes de que este acabe, de manera que es la madre quien puede ir por él a la Sierra para regresar juntos hasta Madrid.

"Ternura y sables", la segunda parte, intenta completar de cierta forma el libro por medio de los mismos ejes temáticos, pero esta vez en el cumplimiento con el servicio militar obligatorio a los veinte años, en 1971. La narración continúa, al igual que la primera parte, con las actividades y tareas diarias de los nuevos reclutas en Valladolid, las cuales debían, en principio, ser llevadas a cabo con la mayor obediencia para aprender la disciplina necesaria que se requiere en el contexto militar. Muchas de las situaciones narradas en esta segunda parte tienen que ver con las complicaciones que encontraba el protagonista para calzar en un grupo tan heterogéneo debido a su natural timidez, en donde primaba un comportamiento típico de jóvenes machistas y prejuiciosos.

Al igual que en la primera parte, el protagonista teme que su personalidad no sea comprendida y que sus diferencias lo hagan apartarse de todos, por lo que se refugia en su lado académico para poder disimular un aspecto que consideraba mucho más sensible de ser atacado, su homosexualidad, en especial al formar parte de un entorno tan agresivo y cerrado. Muchos de los hechos narrados están dirigidos hacia la descripción de situaciones eróticas que se daban entre los compañeros para acentuar esa falta de conocimientos del protagonista en el área y al mismo tiempo el deseo que tenía de formar parte de ello. Después de la experiencia en el cuartel de Valladolid, el protagonista regresa a Madrid para continuar con sus estudios universitarios.

\section{La escritura de la memoria}

Los elementos paratextuales ${ }^{3}$ que ayudan al lector a ubicar el texto dentro de un contexto específico de lectura son pocos, pero muy efectivos, precisamente porque no plantean ambigüedades o dudas respecto del género que se va a leer. De esta forma la editorial clasifica el libro como parte de una colección de memorias, ubicando este calificativo desde la portada. Por otro lado la contraportada nos confirma algunas de las características sobresalientes que tiene esta narración dentro de las producciones literarias del yo; dice: "Patria y sexo no es una autobiografía al uso, sino dos segmentos de ella, que tienen en común el modelo castrense".

Es evidente que, dentro del discurso popular, significantes como "autobiografía" y "memorias" tienen una importante cercanía y no presenta gran problema utilizarlos con valores prácticamente idénticos, de modo que para el caso de estas producciones que giran alrededor del texto central (paratextos, entrevistas, artículos periodísticos, presentaciones, etc.) muchas veces no se recalca el matiz existente entre ambos términos. Lo que sí queda claro es el carácter de escritura del yo y una previa ubicación de la correspondencia entre el escritor (a partir de su nombre propio) y quien sea el sujeto de la narración dentro del texto propiamente dicho. ${ }^{4}$

Patria y sexo se divide en dos partes muy diferentes por el contexto y época que se narra en cada una, pero tienen evidentemente una gran cercanía al englobar las dos temáticas más importantes de la generalidad del texto. Desde el punto de vista de la organización estructural de la narración, ambas partes muestran una gran cercanía, ya que poseen una misma estructura, perspectiva y estilo narrativo. Por esta razón es posible citar ejemplos de una parte que se pueden generalizar para la otra como parte de un continuum narrativo. 
Una última y más clara ubicación del texto dentro del ámbito de las memorias es la que incluye el mismo autor como nota final, en ella se hace primero una breve reflexión sobre los temas centrales del libro, luego explica un poco más el contexto de producción o el proceso de escritura:

La primera parte la escribí, urgido por un tema que llevaba muchos años dentro, entre el 5 de mayo y
el 5 de octubre de 2000 . Sentí - al poco de acabarlo- que ese librito necesitaba otra parte. Pero esa,
complementaria, y algo menos acre, no surgió sino tres años después. La escribí entre el 30 de junio y
el 27 de noviembre de 2003 . Son memorias parciales. Estos es, quieren decir toda la verdad, pero
se restringen a un tema casi único. En aquellos tiempos me pasaron, además, otras muchas cosas,
lógicamente (la negrita es mía) (De Villena, 2004, p. 253)

En esta nota no solo se confirma la clasificación memorialística, sino que también el autor define sintéticamente lo que implica una "memoria" y su característica más importante: la restricción temática. ${ }^{5}$ El autor expresa su objetivo de desarrollar más ampliamente las vivencias que tuvieran que ver con el erotismo en la juventud y las enseñanzas que el Estado transmitía sobre el patriotismo dentro del entorno de la dictadura franquista. La última afirmación de la cita coincide con la definición que se da normalmente de memorias como parte de las escrituras del yo, en la cual se considera que hay una preponderancia de los hechos entorno al yo que cuenta, y no solo su experiencia singular. A este respecto se refiere RomeraCastillo cuando sintetiza las características básicas de los diferentes tipos de escritura del yo:

\footnotetext{
He aquí la clave de las memorias: dar cuenta del uno en los demás, del yo y lo que sucede. Todo consiste en cambiar el objetivo de la cámara de filmación, en pasar de un primer plano de introspección subjetivista a una panorámica más amplia en la que tengan cabida tanto los demás hombres que conviven con el que se confiesa como los ámbitos sociales en los que se articula (Romera-Castillo, 1981, p. 40)
}

De esta manera, a partir de todos los elementos encontrados previos a la lectura del texto como tal, el lector puede esperar un panorama relativamente amplio, más allá de la sola intimidad del autor, en el que se narran los acontecimientos. La concreción de este objetivo básico y puntual de la memoria como forma de escritura en Patria y sexo se puede comprobar en el hecho del enfoque sobre dos momentos de la vida del autor vinculados por el acercamiento a la vida militar y en general a los discursos de construcción de la patria. Prueba de esto se puede encontrar en la comparación entre Ante el espejo y Patria y sexo, ya que en ambos se encuentra el relato del campamento de la OJE (evidentemente con diferencias importantes en el enfoque, el tratamiento de los acontecimientos e incluso en inconcordancias con los personajes), pero en el primero, es parte breve de un relato mayor de conformación de la identidad personal desde la infancia, en cambio el segundo se centra en los dos temas descritos y en los recuerdos de los acontecimientos que mejor los pueden retratar.

\subsection{Memoria y retrospección}

La organización de la narración en cada una de las dos partes del texto ("Filos del alba" y "Ternura y sables") se da de forma cronológica, de manera que hay un orden claro de los acontecimientos; pero también se pueden diferenciar dos momentos distintos desde los cuales el narrador habla. Primeramente el presente del narrador que coincide con el del autor quien rememora, hace comentarios desde la distancia temporal, evalúa algunos hechos, etc. Y otro en el que habla desde el yo que ha dejado de ser, desde la construcción del discurso que crea el yo de la memoria.

La escisión entre estos dos sujetos constituye la ilusión de temporalidad y al mismo tiempo de simultaneidad entre ellos. Dicho corte es indispensable a la hora de configurar el 
discurso autobiográfico en el que ambos deben formar una sola persona junto con el nombre del autor:

\footnotetext{
Me parece - mirándome ahora- que nunca fui sino superficialmente católico y acaso por ello me gustaba ese ritual de la misa [...] (De Villena, 2004, p. 39)

Creo yo -viéndolo desde hoy- que aquel llamado periodo de instrucción de casi dos meses no tenía como fin que aprendiéramos nada específicamente militar, salvo la disciplina (De Villena, 2004, p. 199)
}

En las citas anteriores es posible diferenciar la voz del narrador que reflexiona sobre los acontecimientos descritos del pasado como parte de su ejercicio de retrospección, el cual le permite reconstruir, seleccionar y darle un sentido narrativo a una parte de su vida. La retrospección conduce también hacia un intimismo que lleva al escritor por un repaso de los hechos trascendentes dentro del texto; el espacio íntimo se conjuga con la visión del contexto, como lo es para este caso el proceso por medio del cual los mecanismos estatales van formando una idea de lo nacional desde la infancia de los ciudadanos. Así entonces, no se centra en una dirección de la conformación del yo de manera general, sino en aprendizaje cívico y erótico. Para el caso del erotismo en la adolescencia es más evidente el intimismo, ya que es narrado desde una perspectiva casi confesional en la que un niño observa la explosión hormonal de sus compañeros y la suya propia sin hacer comentarios, más que los internos: la voz interior se organiza como una suerte de secreto inconfesable en el momento del recuerdo.

De acuerdo con Puertas-Moya (2004a, p. 24) "La retrospección supone una interpretación o una exégesis explicativa a sucesos inconexos que tuvieron como protagonista al autor de la narración", y es precisamente lo que se puede encontrar a través del texto, como lo ejemplifican las citas, en los múltiples momentos en los que el narrador comenta directamente los hechos contados desde su presente de narración. Evidentemente esto se da no solo de forma explícita, sino que atraviesa el texto completo de manera implícita, ya que el narrador pone de manifiesto su ideología y sus preferencias por medio de la organización y el estilo narrativo de los hechos.

La estructura retrospectiva del texto memorialístico o autobiográfico en general, presenta la memoria como organizadora y como elemento básico para el narrador en tanto agente activo del relato. Gracias a ella el sujeto es un sujeto autobiográfico. En Patria y sexo el narrador hace constante referencia al funcionamiento de la memoria para conformar la narración, de manera que se manifiestan olvidos e imprecisiones sin tratar de justificarlos o encubrirlos para tener mayor exactitud o veracidad:

\footnotetext{
La memoria, en el recuerdo, selecciona unas cuantas imágenes, a veces pocas pero singularmente precisas, y tan nítidas como a menudo irrelevantes en apariencia (De Villena, 2004, p. 20)

Aunque algo olvidaré sin duda, no me jacto de precisión absoluta (De Villena, 2004, p. 42)

No recuerdo haber hablado mucho ni con mi primo Mario ni tampoco con Tito. No recuerdo conversaciones, solo palabras, giros (De Villena, 2004, p. 94)

Me parece recordar (pero el aturdimiento es mal consejero de la memoria) que, a través de la megafonía, empezaron a dar nuestros nombres (De Villena, 2004, p. 136)
}

Las características anteriores le confieren al texto una mayor fluidez y cercanía con el lector por el hecho de crear una ilusión de sinceridad por parte del sujeto de la enunciación, en la medida en que este reconoce sus limitaciones en la capacidad de recordar fielmente todos los acontecimientos que se pretenden narrar. De esta manera, vemos que el texto memorialístico pretende dar impresiones de una época desde una perspectiva íntima, personal y sin un rigor académico que aleja al lector del rigor supuesto en los textos de carácter autobiográfico. De 
esta manera el recurso básico de la memoria funciona siempre como una relectura de un sujeto que ha dejado de existir, lo cual permite la reflexión interpretativa del pasado.

\subsection{Elementos del pacto autobiográfico}

El hecho de que la narración se dé siempre en primera persona facilita la ilusión discursiva que lleva a un mismo plano los diferentes sujetos y les otorga una misma voz y existencia. La primera frase: "Nunca he querido ir a donde me han mandado" (De Villena, 2004, p. 6) introduce de una vez la primera persona de forma categórica como narrador y protagonista. A pesar de que no hay en todo el texto mención del nombre del protagonista, no hay ningún problema en implicar la vinculación con el autor. Inclusive más adelante hay una importante referencia que los relaciona directamente por medio de un poema (más allá de todos los hechos narrados que tienen que ver con la vida del autor, los cuales no necesariamente el lector los conoce) :

\footnotetext{
Y para distraerme - o porque era mi sendero propio - pensaba en la poesía japonesa, tan amante de las sutilidades. Las carreteras desenvuelven/ las alfombras azules de la madrugada. Este final (verso y medio) se me ocurrió entonces, mientras iba hacia Valladolid en automóvil para la revisión médica militar. (Está en mi poema Raso en la autopista) (De Villena, 2004, p. 42)
}

En la cita anterior se encuentra un elemento único en Patria y sexo, y es precisamente la correspondencia directa del narrador con el autor al hacer referencia a otro de sus textos, en este caso el poemario Sublime Solarium de 1971, primer libro publicado por Luis Antonio de Villena. Este intertexto explicado por el mismo narrador es otro de los elementos capitales que sella el pacto autobiográfico, a pesar de que para este momento ya es muy claro para el lector que debe interpretar que lo contado en la narración corresponde con hechos de la vida del autor, de todas formas funciona junto con los otros elementos descritos anteriormente como parte de las características de la narración autobiográfica que se encuentran en el texto.

Puertas-Moya (2004a, p. 36) al hablar de algunas características sobresalientes del pacto autobiográfico, hace referencia a la honestidad por medio de la cual normalmente la narración "se convierte en una palabra de honor sobre la que se juramenta la verdad", evidentemente la medida de esta honestidad nunca es clara, sino que es algo que se pacta al tomar la lectura como la escritura de las memorias.

\subsection{Sinceridad y referencialidad}

Debido a que en muchísimos casos no es posible hacer una constatación de la mayoría de los hechos narrados en un texto autobiográfico, es necesario comprender el concepto de sinceridad más allá de la contraposición entre mentira y verdad o para el caso de los textos literarios, entre ficción y no ficción.

Es claro que hay una serie de señas a partir de las cuales se puede encontrar la coherencia de la narración autobiográfica por la correspondencia con acontecimientos históricos, lugares y épocas en los que al autor ubica el transcurso de su vida. Esta vinculación entre la narración y la "vida real" se va entretejiendo dentro del discurso para crear la necesaria ilusión de referencialidad como reconocimiento del yo en el sujeto narrado. La percepción lectora de esta autorreferencialidad tiende siempre a identificar sin problema ambos sujetos en uno mismo como parte de la colaboración del lector dentro del pacto. De tal manera en reflexiones del narrador como la siguiente, se pueden observar la referencia al sujeto que dejó de ser a partir de la rememoración y del autoanálisis: 
Sin planteármelo a las claras quería verme y sentirme a mí mismo como un ciudadano refinado y distinto, alguien (una vez más) ajeno a lo militar, y a lo que ello significaba en España. Mucho recordábamos en el cuartel la obviedad etimológica: civilización tiene que ver con civil (del latín civilis, ciudadano) y como se nos recordaba casi de continuo un militar era lo opuesto a un civil (De Villena, 2004, p. 164)

En la cita, el narrador trata de comprender los comportamientos de ese sujeto que él mismo ha dejado de ser y que ahora tiene la necesidad de analizar a la luz de un nuevo contexto. Así entonces el narrador estructura la organización central de la narración, es decir que partiendo de sí mismo y de sus intimidades trata de explicarse de qué manera se conformaron, en dos momentos específicos de su vida, el concepto de patria y las primeras nociones de erotismo.

Podemos también retomar aquí el concepto de sinceridad introducido anteriormente como una manera de desarrollar la organización narrativa. Para esto se puede traer a colación lo que menciona Puertas-Moya (2004b, p. 70) al respecto, quien menciona que es necesario ir más allá de la necesidad de encontrar la verdad en el texto como un rasgo de sinceridad, sino que "es preciso que el punto de vista adoptado para encarar la narración demuestre esa disposición autocrítica a aceptar que lo que uno cree verdadero puede ser erróneo". En este sentido la sinceridad está determinada por la posición que toma el autobiógrafo a la hora de presentar su perspectiva o su versión de los hechos, así entonces se supone e introduce la consciencia del posible error y no la de un narrador que conoce todo lo que cuenta. Por lo tanto, típicamente se considera que cuando la narración se muestra como una confesión íntima en donde el tema gira en torno al yo más profundamente, el lector percibe esta introspección como muestra de la sinceridad (Puertas-Moya, 2004b, p. 73).

\section{La imagen personal}

Yo era un niño distinto (un niño que dejaba de ser un niño) y que tampoco sabía por qué era distinto (De Villena, 2004, p. 59)

A través de la lectura del texto es posible encontrar una variedad de referencias relacionadas con el intento del protagonista de encontrarse consigo mismo. Esta necesidad se ve subrayada en las diferencias que él podía sentir respecto de su entorno y de sus compañeros. Por esto, el primer relato (sobre el campamento) es el que coincide más con un intento de formación de personaje, en donde se empiezan a recibir las primeras nociones de sobrevivencia y de utilidad para la vida posterior. Todo esto después de tener que dejar por unas semanas la comodidad de un hogar consentidor y burgués. Podemos identificar en la diégesis las reflexiones del narrador acerca de la tentativa de definir esa personalidad aislada, esto al tomar conciencia de ser "un niño distinto".

En el segundo relato, "Ternura y sables", el narrador trata de justificar su recurrencia a discursos intelectuales, y a veces incomprensibles para su interlocutor, con el objetivo de distraer la mirada del otro. Su posición de intelectual debía explicar la diferencia o rareza percibida por los otros como poses de "sabiondo". El narrador pretende así evitar el enfrentamiento con la realidad de su verdadera diferencia: la identidad sexual. En la cita siguiente hace un autorretrato que corrobora los aspectos anteriores:

Hacía muy poco tiempo que llevaba gafas — en realidad apenas las necesitaba- pero me apertreché de las más viejas que tenía [...] y procuré, algo caídas, dar con ellas un aire de sabiondo y despistadillo. Por fortuna el uniforme de faena me quedaba holgado - era yo flaquillo - y entre tales holguras, mal puesta 
la gorra de visera y las gafas dichas, me preparé un conjunto (y no era yo un chico feo, no, a mis largos diecinueve años) con aire de ratón de biblioteca levemente pirado (Villena, 2004, p. 170)

Podemos leer aquí una doble intención, en un primer nivel el narrador reconstruye el yo de esa época a partir de sus recuerdos fragmentados, el cual es a su vez una construcción artificial del protagonista quien se traviste para desviar la mirada de los otros y así conservar su rareza. Sin embargo esta se funda en una fuente distinta: el intelectualismo. De esta manera el narrador confiesa haber pasado muchos años simulando ser otro y construyéndose una identidad en gran medida distinta de la que él sentía realmente suya. Esta estrategia es muy interesante como parte del proceso de construcción, no solo de la identidad personal, sino también del texto autobiográfico, el cual funciona como un desvelamiento de la identidad auténtica (entendida esta como la que el protagonista sentía más suya en ese momento de su vida).

\subsection{La encarnación del deseo}

El sexo empezó para mí realmente cuando lo vi reinar, aquel verano, bajo la lona tosca de la tienda. Un sexo espontáneo, bruto, brillante y naturalmente inclemente como un gran árbol en los bosques de lluvia (De Villena, 2004, p. 36)

El epígrafe que abre este apartado ilustra muy bien el momento en el que el protagonista siente más curiosidad por la naturaleza del sexo y la relación que este tiene con él mismo, muy especialmente al ver que su curiosidad se dirigía exclusivamente hacia el sexo masculino. Por este motivo el protagonista inicia un proceso de descubrimientos y represiones para poder conjugar el deseo con las contradicciones que encuentra en una sociedad tradicional y machista.

Como cualquier niño de la época, el conocimiento sobre el sexo y las sexualidades al borde de los once años es muy escaso, especialmente porque la vía de acceso al mismo tenía un carácter típicamente escolar y biológico-anatómico. A esto se suma la ideología imperante en la España de los años sesenta bajo el régimen franquista. En este contexto es muy complicado acceder a nociones que revaloricen las sexualidades, por el contrario la principal tendencia estaba dictada por la iglesia católica y la condenación del pecado. El factor familiar, por otra parte, tampoco tenía gran influencia de manera educativa, sino que contribuía a la reafirmación de los valores religiosos y condenatorios, lo que es el caso del protagonista y su ambiente burgués venido a menos.

El primer acercamiento descrito tiene que ver con uno de los compañeros del campamento, quien le pide al protagonista que lo acompañe al lugar donde la mayoría de los chicos va a hacer sus necesidades. La sola idea de poder estar ante el cuerpo semidesnudo de un igual genera gran curiosidad y excitación, cosa que el protagonista empieza apenas a entender. El narrador lo explica de la siguiente forma: "Para mí no tuvo nombre, entonces, ese deseo tan inconcreto como nítido, tan precioso como vaporoso. Quizá era la nostalgia masculina de un compañero de habitación" (De Villena, 2004, p. 36). Hay en principio una confusión entre el erotismo y la camaradería, entre la necesidad de sentir la compañía masculina en la amistad o la evidencia de la atracción física por el cuerpo. De acuerdo con el narrador estas primeras sensaciones eran vagamente interpretadas debido al gran desconocimiento en la materia y al anterior aislamiento relativo en un entorno complaciente con la madre.

Es necesario señalar que uno de los motivos que se mencionan para justificar la entrada del niño en el campamento es la dependencia de su madre y el calificarlo de muy consentido, 
lo cual "afectaría" su formación en el ámbito de la masculinidad. De esta forma hay una preocupación previa como parte de las justificantes del ingreso, ya que para corresponder con los cánones de masculinidad vigentes es necesario recibir toda una formación en lo concerniente a la virilidad, formación que, por excelencia, es impartida por el padre, el cual para este caso está ausente. ${ }^{6}$ La muerte del padre es presentada constantemente como uno de los causantes de la llamada diferencia del protagonista:

\begin{abstract}
¿Qué le ocurrirá a este niño, quizá demasiado enmadrado? ¿No habría que volverlo más fuerte, más recio, más viril, a ese niño que no tenía padre? Alguien -probablemente algún profesor, acaso también el antiguo pediatra a quien veneraba: Mándele a un campamento, en verano. Entre chicos, teniendo que valerse por sí mismo, se hará más fuerte, más hombre. No le pasa nada, simplemente es tímido y ha sido muy mimado (Villena, 2004, p. 18)
\end{abstract}

Esta descripción es una de las diferentes explicaciones o posiciones que se pretenden tomar - ya sea de otros o de parte del mismo protagonista - respecto de la rareza del niño. El protagonista se veía a sí mismo como "un niño al que no le habían enseñado a andar. O no le habían enseñado a valerse, a defenderse a constituirse, lo que posiblemente sea más grave..." (Villena, 2004, p. 15). Estas ideas se confirmaban cuando el protagonista se siente provocador de lástima al haber perdido a su padre desde la infancia. Esto también explica que la madre enviara a dos de los primos del niño para que participaran del campamento y al mismo tiempo cuidaran a su primo menor.

Ciertamente el campamento daría al niño una serie de experiencias que él no podría tener en su entorno normal, las cuales lo llevaron a descubrir una realidad más allá de sus expectativas infantiles. Para la estructuración de la masculinidad en la sociedad patriarcal es necesario atravesar ciertas pruebas que confirmen el éxito en la transición de niño a hombre. En este sentido el campamento funciona como un rito de iniciación para el protagonista, el cual lo llevará a tomar conciencia, al menos en parte de las exigencias de la sociedad y del Estado y la relación que estas tienen con el hecho de ser hombre.

Al tener que compartir con compañeros de edades similares, en especial un poco mayores, tenía la oportunidad de introducirse en su mundo y evidentemente ese mundo está lleno de alusiones sexuales, por ser un terreno desconocido que genera mucha curiosidad. Por esto el contacto entre los jóvenes llevaba muchas veces a hacer comentarios acerca de su cuerpo e incluso terminar en masturbaciones grupales, lo cual empezaba a llenar de curiosidad y excitación al protagonista:

\footnotetext{
Se decía [...] que dentro de aquella tienda, muchas noches, abundaba el sexo. Orgía no puede ser palabra de esas edades. Los grandes chicos jugaban a las cartas, bebían cerveza, fumaban y seguían adelante... ¿Se masturbaban? ¿Follaban? Un niño de mi edad no recuerda - porque no las sabía- tales palabras. Recuerda instintos, sensaciones. Allí había sexo. Se propagaba su luz, su aroma, su fuerza... (De Villena, 2004, p. 18)
}

Esta conciencia del sexo que se empezaba a dar en el joven se manifiesta de forma ambigua. Él no comprendía muy bien lo que pasaba, pero sabía que sentía una gran atracción por algunos de sus compañeros, en especial cuando se daban estos encuentros secretos. Debido a esto y a la timidez el narrador asegura que sus primeras experiencias en relación con el sexo se dieron desde la observación:

Yo aprendí mal el sexo adolescente. Porque la de mirón (y no tuve otra) no es la posición idónea para ese aprendizaje en que la carne pide carne, como compañerismo, como amistad o como esa gresca guerrera que conocen todos los que han visitado el espartano clima de los gimnasios jóvenes (De Villena, 2004, p. 72) 
El protagonista tuvo siempre una participación pasiva en todas las situaciones de tinte sexual ocurridas durante el campamento. Este hecho es lamentado por el narrador al no haberse podido iniciar de forma activa más pronto.

Es precisamente en el otro nivel de narración, es decir en los análisis y ordenación de las memorias donde se encuentran las observaciones que tienen que ver con el hecho de ser gay y verse como tal. Es claro que el protagonista aún se encuentra muy lejos de llegar a estas conclusiones. Sin embargo es al final del relato que el narrador enlaza sus ritos iniciáticos - no en la virilidad tradicional sino en el homoerotismo - con la conciencia de sí desde el momento de la narración, en donde el ejercicio de la escritura autobiográfica funciona como puente entre ambas épocas para llegar a un conocimiento íntimo que no se tenía antes. La comprensión a la que se llega es el nacimiento del miedo a enfrentar su identidad que empieza a latir más fuertemente. El narrador marca el campamento como el inicio de sus intentos de encubrimiento, el inicio de un viaje a la doble vida:

\footnotetext{
Solo lo tocaba y lo presentía [el miedo]. Intuía que era terrible y que salir de mi cuarto, de mi casa, de mi soledad no era sino el símbolo de otro miedo más estrepitoso y más terrible... El terror a ser crucificado, insultado, por la atroz mayoría. Dentro del armario, protegido, oscuro -creí con dolor-, gozaría siendo distinto, decadente, un sioux lejano como los gatos, como los gavilanes o los búhos sublimes (De Villena, 2004, p. 107)
}

La metáfora del armario aparece en la cita anterior como una importante referencia a lo que es la vida por venir, después del regreso del campamento. La toma de conciencia del erotismo es el primer paso para que el protagonista se encierre más en la necesidad de ocultarse y crear una versión de sí mismo que distraiga la mirada de ese hecho.

\subsection{La 'mili' y el sexo}

El segundo relato, "Ternura y sables", inicia cuando el protagonista cuenta con diecinueve años, aunque muchos de los miedos y la timidez que caracterizan al niño del campamento siguen muy presentes. En este caso el contexto implica una mayor conciencia de sí mismo en relación con la vinculación con los demás y la vida erótica en general, sin embargo el protagonista aún carece de experiencia y sigue relegado en el escondite del armario que se inaugura en el relato precedente.

El servicio militar, al igual que lo fue el campamento para el niño en su momento, implica una fuerte prueba de la masculinidad, un espacio en donde se baten los jóvenes para demostrar su superioridad sobre el otro y vencer el peligro de ser tomado como homosexual o feminizado. Ante este hecho palpable, el protagonista sentía mucha ansiedad de iniciar el viaje, a lo que se preguntaba: “Qué harían con mi supuesta rareza? ¿Qué otras pruebas tendría que pasar?” (De Villena, 2004, p. 119). Esto lo lleva a evitar el regimiento con fama de ser más fuerte y entrar, gracias a influencias familiares, en el Ejército del Aire, donde se suponía que había un ambiente un poco menos estricto y con reclutas mejor formados. De esta manera, el protagonista iba poco a poco sobrepasando las dificultades de un ambiente tan cargado de machismo, evitando ejercicios con prescripciones médicas, intercambiando las tareas más duras por dinero, etc. Pero especialmente trataba de evitar la inminencia de la injuria, es decir la descalificación de su persona por causa de la puesta en duda de la sexualidad, y de la virilidad en concreto, esto lo hacía al darse una fama de filósofo intelectual que explicara sus extravagancias: "Porque todo este teatro (pequeña escenografía, si se prefiere) tenía un muy práctico y deseado fin. Si no se olvidaban de mí, si me miraban — siempre me ha ocurrido- 
que, al menos, me dejaran en paz. Ser llamado el filósofo se me antojó un excelente escudo" (De Villena, 2004, p. 175).

"Todo era sexo" dice el narrador al referirse al ambiente que se vivía en el cuartel, por lo cual era un espacio idóneo para experimentar. En el texto se encuentran muchas situaciones en las que el protagonista se ve tentado a tomar una posición activa dentro de las posibilidades eróticas que se presentaban, pero su natural timidez y el miedo a ser denigrado por homosexual se lo impidió. Por estas razones los encuentros eróticos se dan una vez más como un tercero que observa, es decir fue siempre en su juventud un afanado voyerista:

\footnotetext{
Pero como supe algo después el sexo era diurno. Y no en la cama (imposible tanta evidencia) sino, por lo general en las cabinas de los váteres. Incluso oí -estupefacto- que al canario se la metían allí dándose jabón en el rabo. La mayoría se masturbaba en solitario -como estuve a punto de pillar a Pedro- pero más adelante vi que algunos, a los que discretamente observaba de lejos, entraban juntos (De Villena, 2004, p. 183)
}

Eran muchas las historias que podían llegar a los oídos del protagonista que relataban los encuentros eróticos de jóvenes reclutas pertenecientes a su mismo grupo, sin embargo estas situaciones eran vistas de forma muy natural por el común de los asistentes, ya que el espacio típicamente masculino que impera, junto con la efervescencia de las hormonas de la juventud, provocan un ambiente muy cargado de erotismo, ya sea desde la palabra - en los comentarios, chistes, historias, etc. - o desde los actos como los que se describieron anteriormente. Es interesante también señalar que estas prácticas eróticas dentro del cuerpo militar de reclutas jóvenes no son vistas como acciones que atenten contra la virilidad al erotizarse con el cuerpo de un otro masculino, sino que se dan en un contexto donde abundan tanto el sexo como la falta de experiencia con respecto a él, por lo cual hay aún mucha curiosidad mezclada con el clima de competencia.

A pesar del clima que se podía encontrar en este contexto militar, el protagonista no tuvo sus primeras experiencias sexuales en dicho lugar, sino que, siguiendo un poco el comportamiento del relato anterior, el protagonista se dedica a indagar, a observar las conductas de los participantes y a fantasear. El mismo narrador lo reconoce al deplorar lo tarde que se inició en "los placeres del sexo", esto por una serie de razones que se conjugan para producir un sujeto reprimido y tímido.

Además de las conversaciones constantes sobre el sexo, las masturbaciones solitarias o en grupo, el protagonista se encuentra con algunas otras prácticas que captan de inmediato su atención, una de ellas es la historia del canario que algunos de los compañeros contaban, a quién le solicitaban favores sexuales directamente al considerarlo homosexual. La otra situación que le produjo un impacto fue la pareja de jóvenes que parecía ir un poco más allá de la simple práctica adolescente:

\footnotetext{
Vi cómo se bajaban -sin quitárselos- los calzoncillos y los oí jadear y revolcarse (quizá dos veces) y luego, como en un haz de luz, vi el prieto y perfecto culo blanco del chico estatuario, que intentaba bajarse más el calzoncillo, que le ataba, mientras oí al otro, casi enseguida susurrar: Joder, cabrón, me estás pringando entero [...] Por lo demás confieso que en ese mismo instante dejé de mirar. No soportaba tanta maravilla [...] me hubiese gustado acercarme (¿quién habría soñado en hacerlo de veras?) y pedirles, sonriente y empalmado como estaba, que me dejaran jugar con ellos (De Villena, 2004, p. 188)
}

Como vemos la confrontación del protagonista con un ambiente masculino altamente erotizado se constituye dentro del recuerdo como un momento determinante para la formación personal y para las ideas en torno al sexo. El espacio militar se presenta como el lugar ideal 
de transmisión de los esquemas heterosexistas gracias a los cuales se establece la norma, es decir una normalidad heterosexual y obligatoria. Los posibles roces homoeróticos son aquí justificados con la juventud y la cercanía de los cuerpos - elementos característicos del servicio militar - siempre y cuando permanezcan como prácticas excepcionales. Para el protagonista, estos roces forman parte de la formación y aprendizaje en una sexualidad distinta de la cual era ya consciente desde la infancia.

\section{Conclusiones}

[...] el sexo y la patria, bajo todos los colores, deben, debieran ser compatibles [...] ¿Por qué habrían de divorciarse patria y sexo? ¿Por qué nos siguen sonando antinómicos ambos conceptos? (De Villena, 2004, p. 252)

La estructura de Patria y sexo como texto de memorias permite al autor el hecho de profundizar dos elementos que fueron determinantes para su formación en la sexualidad y su comprensión de un proceso de aceptación posterior como homosexual: en este caso la patria y el sexo se encuentran íntimamente ligados como muestra de la imposición organizada de la norma heterosexual por medio de la reglamentación ciudadana y de la disciplina militar. Dentro de esta estructura, el pacto autobiográfico que identifica directamente a Villena como protagonista del relato se ve confirmado constantemente desde los elementos paratextuales hasta las referencias intertextuales dentro de la narración, lo cual guía al lector dentro de una narración que se presenta a sí misma como una introspección sincera en la infancia y juventud.

Para cerrar esta vinculación entre los dos elementos centrales del título, "Ternura y sables" finaliza tratando de reunir diversas propuestas desarrolladas en la totalidad del libro, en especial alrededor de los dos temas centrales que tienen que ver con un proceso de aprendizaje, por un lado de una cuestión natural como el erotismo y el sexo, y por otro un aprendizaje de los valores que en la época se consideraban parte de la ciudadanía. Patria y sexo presenta un protagonista que va descubriendo poco a poco las posibilidades del placer, pero sobre todo desde un punto de vista eterno o idealizado, es decir como espectador que desea y se erotiza en la mirada. Esto es más comprensible en el primer relato, donde sigue siendo un niño tímido, pero el segundo relato muestra una continuidad de estos comportamientos, ya que el protagonista sigue siendo inexperto y voyerista. Por estos motivos el narrador lamenta el hecho de continuar escondido en su sexualidad y condenado al silencio para le época de los veinte años: "Acaso lo expliquen la mucha emoción y aquel íntimo daño que nos obligaba -a mí, y a muchos que eran como yo- a mantener silencio y callar, como si lo más limpio y noble que hubiera en nosotros debiera permanecer inconfesable y oscuro" (De Villena, 2004, p. 208).

En relación con los discursos de la patria se puede ver constantemente un reproche a las influencias fascistas que perduraban en la formación de los niños, para el caso del campamento, y para el caso del servicio militar se critica la abundante presencia de militares ignorantes, machistas, homófobos, que forman parte de un organismo tan determinante para la nación. Sobre esto concluye Villena: "Patria y sexo. Del sexo me quedó el deseo de ser. El deseo de realidad y pulcritud paganas. ¿Y de la patria? Lo que ya pudiera saber, porque allí se vislumbraba - ni siquiera se llegaba a aprender del todo - una patria tan irreal como remota" (De Villena, 2004, p. 250). Estas líneas finales demuestran un proceso de formación incompleto o fallido: el sexo se queda sublimado en el deseo y la patria se confirma como un ideal lejano. 


\section{Notas}

1. De Villena, L. A. (1982). Ante el espejo, memorias de una adolescencia. Barcelona: Argos Bergara.

2. Juntas de Ofensiva Nacional Sindicalista.

3. Recordemos la clasificación hecha por Genette acerca de esta categoría textual: "Le paratexte est donc pour nous ce par quoi un texte se fait livre et se propose comme tel à ses lecteurs, et plus généralement au public. Plus que d'une limite ou d'une frontière étanche, il s'agit ici d'un seuil, ou — mot de Borges à propos d'une préface- d'un «vestibule» qui offre à tout un chacun la possibilité d'entrer ou de rebrousser chemin" (Genette, 1987, pp. 7-8).

4. Nos referimos en particular a la clasificación de la escritura autobiográfica presentada por Philippe Lejeune : "récit rétrospectif en prose qu'une personne réelle fait de sa propre existence, lorsqu'elle met l'accent sur sa vie individuelle, en particulier sur l'histoire de sa «personnalité»" (Lejeune, 1994, p. 14)

5. La clasificación establecida por Lejune respecto de las diferentes posibilidades de la escritura del yo define las memorias como un género en el que no se intenta reconstituir la historia de una personalidad, sino un aspecto particular de la misma (Lejeune, 1994, p. 14).

6. En este punto de la narración se encuentra una importante diferencia con Ante el espejo, en donde se narran brevemente algunos acontecimientos del campamento en la Sierra, pero con justificaciones y personajes cambiados. En Ante el espejo el narrador dice que fue su padre quién decidió enviarlo al campamento, después de divorciarse de su madre, para conseguir que se hiciera 'un hombre', además es la abuela la que lo va a visitar los domingos y lo consiente con dulces y privilegios. En Patria y sexo el ingreso en el campamento es una recomendación hecha a la madre para hacer que el niño sin padre se formara en un entorno más 'viril'. De acuerdo con las características de ambos textos se puede afirmar que Ante el espejo es más ficcionalizado que los demás al poseer más características de este estilo narrativo.

\section{Bibliografía}

De Villena, L. A. (1982). Ante el espejo: memorias de una adolescencia. Barcelona: Argos Bergara.

De Villena, L. A. (2004). Patria y sexo. Madrid: Seix Barral.

Genette, G. (1987). Seuils. Paris: Éditions du Seuil.

Lejeune,P.(1994). El pacto autobiográfico y otros estudios. Madrid: MEGAZUL-ENDYMION.

Puertas-Moya, F. E. (2004a). Aproximación semiótica a los rasgos generales de la escritura autobiográfica. Logroño: Universidad de La Rioja.

Puertas-Moya, F. E. (2004b). Los orígenes de la escritura autobiográfica: género y modernidad. Logroño: Serva.

Romera-Castillo, J. (1981) La literatura: signo autobiográfico. El escritor, signo referencial de su escritura. Por J. Romera-Castillo (Ed.). La literatura como signo. (13-56). Madrid: Ediciones Playor. 
